\title{
Exploring Innovative Leishmaniasis Treatment: Drug Targets from Pre-Clinical to Clinical Findings
}

\author{
Wanessa Santana, ${ }^{a}$ Simone S. C. de Oliveira, ${ }^{\mathrm{b}}$ Mariana H. Ramos, ${ }^{\mathrm{a}}$ André L. S. Santos, ${ }^{\mathrm{b}}$ \\ Silvio S. Dolabella, ${ }^{\mathrm{C}}$ Eliana B. Souto, ${ }^{* d,}$ e Patrícia Severino, ${ }^{\mathrm{a}, \mathrm{f}}$ and Sona Jain ${ }^{* a}$ \\ ${ }^{a}$ Post-Graduation Program in Industrial Biotechnology, University of Tiradentes, Aracaju, Sergipe, Brazil, \\ e-mail: sonajain24@yahoo.com \\ ${ }^{\mathrm{b}}$ Institute of Microbiology Paulo de Góes, Department of General Microbiology, Federal University of Rio de \\ Janeiro, Rio de Janeiro, Brazil \\ ' Laboratory of Entomology and Tropical Parasitology, Department of Morphology, Federal University of Sergipe, \\ São Cristóvão, Sergipe, Brazil \\ ${ }^{d}$ Department of Pharmaceutical Technology, Faculty of Pharmacy, University of Coimbra, Pólo das Ciências da \\ Saúde, Azinhaga de Santa Comba, Coimbra, Portugal, e-mail: ebsouto@ff.uc.pt \\ ${ }^{\mathrm{e}}$ CEB - Center of Biological Engineering, University of Minho, Campus de Gualtar, 4710-057 Braga, Portugal \\ ${ }^{f}$ Institute of Technology and Research (ITP), University of Tiradentes, Aracaju, Sergipe, Brazil
}

Leishmaniasis is a group of tropical diseases caused by parasitic protozoa belonging to the genus Leishmania. The disease is categorized in cutaneous leishmaniasis $(\mathrm{CL})$, mucocutaneous leishmaniasis (MCL), and visceral leishmaniasis (VL). The conventional treatment is complex and can present high toxicity and therapeutic failures. Thus, there is a continuing need to develop new treatments. In this review, we focus on the novel molecules described in the literature with potential leishmanicidal activity, categorizing them in pre-clinical (in vitro, in vivo), drug repurposing and clinical research.

Keywords: leishmaniasis, new targets, pre-clinical, clinical, drug repurposing.

\section{Introduction}

Leishmaniasis is a group of tropical diseases caused by protozoan parasites belonging to the genus Leishmania. ${ }^{[1]}$ There are more than 20 species of Leishmania distributed worldwide and each species can cause different clinical manifestations, which can be grouped into three main clinical forms: cutaneous leishmaniasis $(\mathrm{CL})$, mucocutaneous leishmaniasis $(\mathrm{MCL})$ and visceral leishmaniasis $(\mathrm{VL}){ }^{[2,3]} \mathrm{CL}$ is the most common form of the disease and it is generally painless and chronic. ${ }^{[4]}$ In general, the lesions occur at the sites bitten by the infected sand fly, such as the face, legs and arms. MCL is characterized by lesions that can partially or totally destroy the mucous membranes of the cavities of the nose, mouth and throat, which can lead to disfigurement of the patient with consequent social exclusion. ${ }^{[5]} \mathrm{VL}$ is the most serious manifestation of the disease and it is charac- terized by fever, weight loss, enlargement of liver and spleen, pancytopenia and hypergammaglobulinemia and it may be fatal if left untreated. ${ }^{[6,7]}$ Leishmaniasis predominantly affects the poor population of countries in Africa, Asia and Latin America. Recent estimates indicate that about 350 million of people live in a vulnerable situation with the risk of contracting leishmaniasis. In a global perspective, the disease currently affects around 12 million people worldwide. ${ }^{[8]}$ According to $\mathrm{WHO}$, there are currently 98 countries that are endemic for leishmaniasis; nine of them are endemic only for $V L, 21$ only for $C L$ and 68 countries are endemic for both leishmaniasis forms. ${ }^{[7]}$

Leishmania spp. are digenetic parasites, presenting two main evolutionary forms during their life cycle: promastigote, present in the invertebrate host and amastigote (present in the vertebrate host). The promastigote form is transmitted to the vertebrate 

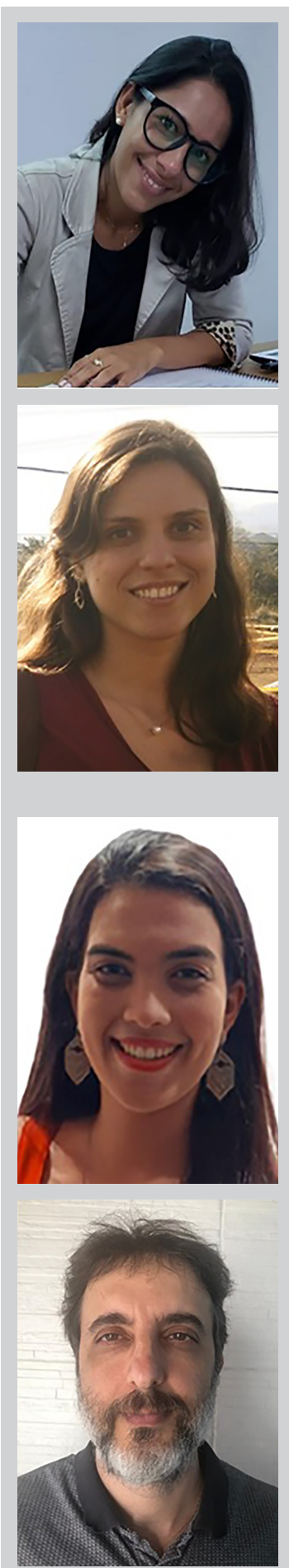

Wanessa Mota received her bachelor's degree in Industrial Biotechnology from Tiradentes University, Aracaju, Brazil and is currently a doctor student working on the mechanism of action, and toxicity of isopentyl caffeate for the treatment of leishmaniasis.

Simone Santiago Carvalho de Oliveira, Postdoctoral Researcher - Summary: I work as a postdoctoral researcher and I have experience with the following topics: peptidases, cytotoxicity, mechanisms of action of chemotherapy, pathogen-host interaction and Leishmania spp. My studies are currently focused on discovering new bioactive compounds that have anti-Leishmania activity and in the study of the mechanism of action of new antimicrobials.

Mariana is studying Pharmacy at Tiradentes University, Aracaju, Brazil, and has an undergraduate research scholarship to work on the in vivo toxicity of isopentyl caffeine for the treatment of leishmaniasis.

Silvio Dolabella is a Pharmacist with Ph.D. in Parasitology from the Federal University of Minas Gerais, Brazil. He has experience in the area of Parasitology, with emphasis on Human Protozoology.

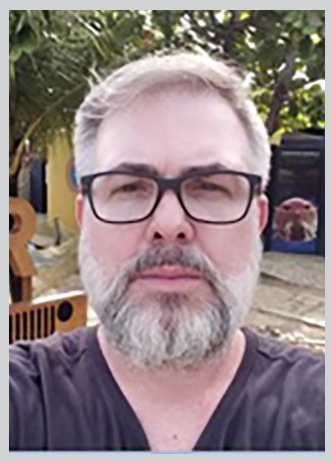

André Luis Souza dos Santos, full Professor - My research group is distinguished by its multidisciplinary nature, with direct involvement of different research institutions from Brazil and from abroad countries, generating productive and effective collaborations in the discovery of novel compounds with promising antimicrobial action as well as in deciphering the molecular mechanisms related to the antimicrobial resistance events.

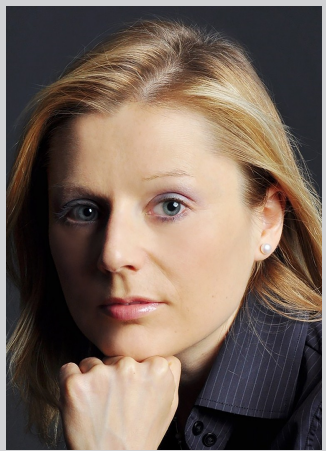

Eliana Souto (Souto, E.B.) is affiliated with the Department of Pharmaceutical Technology of the Faculty of Pharmacy, University of Coimbra, Portugal. Eliana is graduated in Pharmaceutical Sciences from the same University. She holds a Master in Science degree in Pharmaceutical Technology and Pharmacotechnique from the Faculty of Pharmacy, University of Porto, and the Ph.D. in Pharmaceutical Technology, Biopharmaceutics and Biotechnology from the Institut fuer Pharmazie der Freie Universitaet Berlin, Germany. Since August 2012, Eliana Souto holds the Dr. Habil. from the University Fernando Pessoa. Her research lines focus on the design, development, and characterization of new drug delivery systems. Other research interests include the controlled delivery of drugs across biological barriers, e. g., skin, gastrointestinal tract, and blood-brainbarrier. Eliana Souto is Associate Editor, member of the Editorial Board, and reviewer of several international scientific journals.

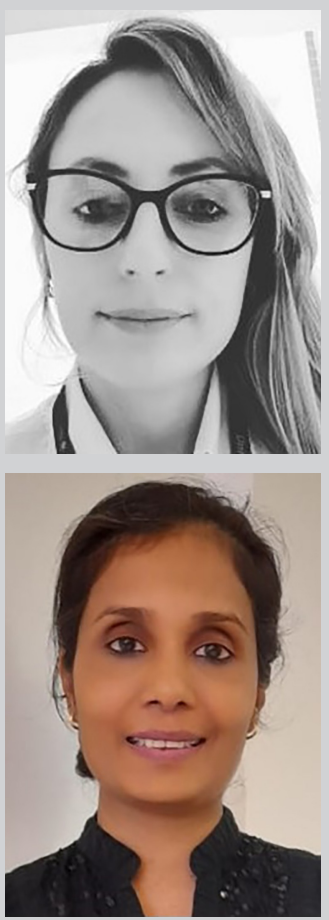

Patrícia Severino, Pharmacist, Master and Ph.D. in Chemical Engineering. Professor at Tiradentes University with experience teaching at the college and postgraduate level. Researcher at Technology and Research Institute coordinating Nanotechnology Lab.

Sona Jain received her bachelor's degree in Microbiology from Sophia College, Mumbai, India, and master's and Ph.D. degrees from Ehime University, Japan, as a Monbukagakusho Scholar. She was a visiting researcher at the Department of Comparative Biosciences at the University of Illinois at Urbana-Champaign, and at the Institute of Nanotechnology, University of Waterloo, and currently works as a professor and researcher at Tiradentes University, Aracaju, Brazil focusing on industrial biotechnology, especially screening and characterization of microbial metabolites. 
host by the bite of infected female phlebotominae sandflies. The promastigotes differentiate into amastigotes in the vertebrate's host, multiply intensely and spread infection (Figure 1). ${ }^{[9-11]}$

Currently, chemotherapy is the basis of antileishmanial treatment. Different drugs are available for use, the choice of medication varying according to the disease form and the geographic region. ${ }^{[12,13]}$ The available drugs are however not ideal, showing high toxicity and low efficacy in some endemic regions. ${ }^{[12,14]}$ Moreover, therapeutic failure, patient recurrence and deaths due to the disease complications are often observed, requiring new efficient treatment options that are less toxic. In this review, we bring together information regarding new molecules with potential leishmanicidal activity. We first describe the drugs currently in use for the treatment of leishmaniasis and highlight their limitations. Then, we relate the new molecules with good potential, classifying them according to the drug development timeline (Figure 2) into pre-clinical (in vitro, in vivo analysis) and clinical phase, also including an extra topic on drug repurposing. Finally, we discuss future perspectives to address the current limitations.

\section{Current Treatment Options and Limitations}

The drugs of choice for the treatment of $C L$ and $V L$ are pentavalent antimonials, commercially available in the forms of meglumine antimoniate (Glucantime ${ }^{\circledR}$ ) or sodium stibogluconate (Pentostam $\left.{ }^{\circledast}\right){ }^{[12]}$ Pentavalent antimonials are registered and licensed in Southeast Asia, Latin America and some Mediterranean and African countries. ${ }^{[12]}$ Although these compounds are highly effective in different parts of the world, like Africa, they have been ineffective in India, due to the emergence of resistant strains. ${ }^{[15]}$ Antimonials have low cost and can be administered intravenously (Pentostam) or intramuscularly (Glucantime), and they have also been applied intralesionally for the treatment of $\mathrm{CL}{ }^{[12,16]}$ Although effective, reports of side effects are common in therapy with antimonials, such as nephrotoxicity, cardiotoxicity (arrhythmia, prolongation of the Q-T interval, ventricular tachycardia), hepatotoxicity and elevated levels of pancreatic enzymes. ${ }^{[12,14]}$ HIV-Leishmania co-infection has also been associated with an increase in the number of recurrence cases after treatment with antimonials, as well as with the increase in the number of deaths. ${ }^{[17]}$ Moreover, treatment with antimonials is long, which,

Ingested amastigote differentiate into procyclic promastigote in the insect intestine

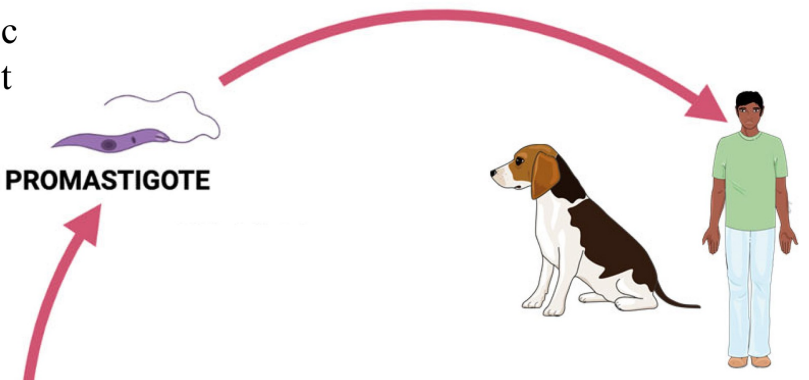
In the mammalian cells promastigote differenciate into amastigote forms

Female sandfly, ingests amastigote form along with the blood

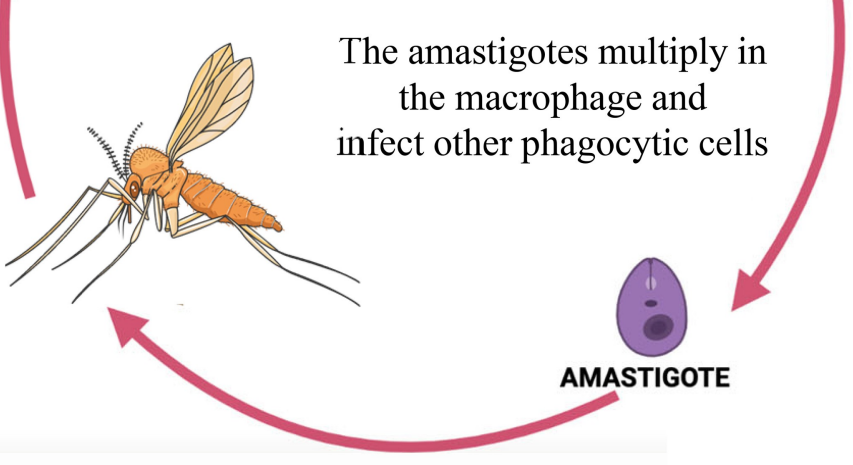

\section{Human stage}

Figure 1. Life cycle of Leishmania in the invertebrate and vertebrate hosts. 


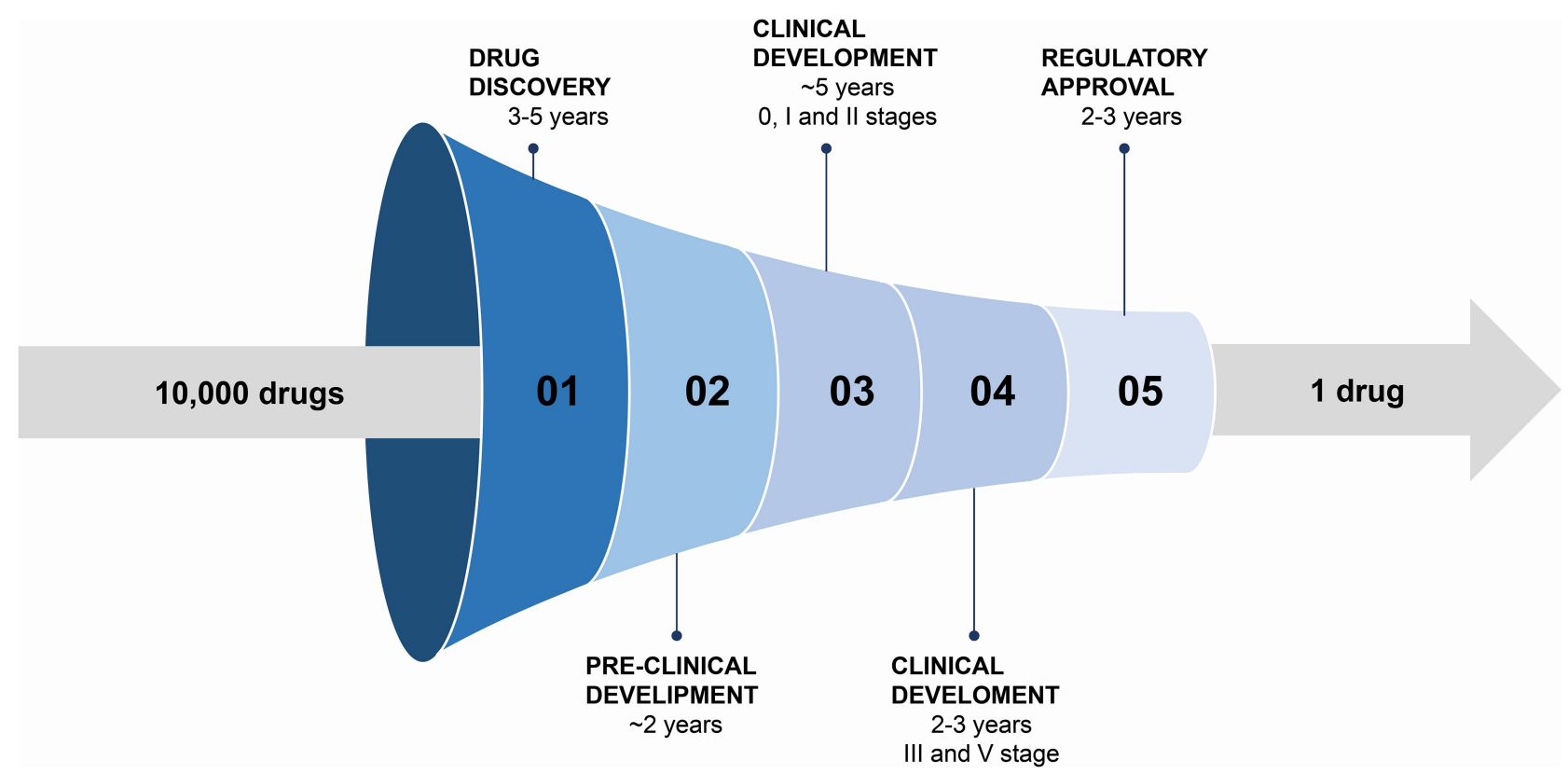

Figure 2. Stages of drug development. The development of a new drug follows several stages such as drug discovery, pre-clinical development, clinical development, and regulatory approval. Researchers begin the discovery of new drugs with potential for the treatment of the disease (for example leishmaniasis) and initiate tests in cells and animals. Then, it proceeds to the clinical research phase with the objective of testing the safety and effectiveness in humans. The development of a new medicine lasts for approximately 15 years before reaching the consumer market.

together with the high toxicity, makes it difficult for patients to adhere to the treatment. ${ }^{[15]}$

Other drugs have also been widely used in the treatment of leishmaniasis, such as amphotericin B deoxycholate $(\mathrm{AmB}){ }^{[12]} \mathrm{AmB}$ is a polyene antifungal that has been used as alternative drug in the treatment of leishmaniasis caused by antimonial-resistant strains. ${ }^{[18]}$ Although highly effective, AmB also has a number of side effects, including nephrotoxicity, electrolyte abnormalities, hypokalemia and myocarditis, requiring hospitalization of the patient and increasing the cost of treatment. ${ }^{[18]}$ In order to minimize these toxic effects, lipid formulations of $A m B$ have been developed, such as liposomal AmB (L-AmB) $\left(\right.$ AmBisome $\left.{ }^{\circledR}\right), A m B$ colloidal dispersion (ABCD) (Amphoci $\left.{ }^{\oplus}\right)$ and $A m B$ lipid complex (ABLC) $\left(\right.$ Abelcet $\left.^{\circledR}\right){ }^{[18,19]}$ These new formulations are just as effective as the original $A m B$, while at the same time showing better tolerability and less toxicity. ${ }^{[16]}$ Liposomal AmB has been the drug of choice in the treatment of patients with HIV co-infection. ${ }^{[20]}$ However, a study in Bihar, India, showed that the use of this drug in the treatment of these patients did not show any reduction in rates of recurrence and mortality compared to HIV-negative patients. ${ }^{[21]}$ Lipid-based formulations of $A m B$ are quickly targeted at the organs where the disease develops, so that other organs, such as the kidneys, are saved, which reduce their adverse side effects. ${ }^{[18]}$ However, although AmB liposomal formulations are effective and better tolerated, they still need to be administered by intravenous infusions, which require hospitalization of the patient for treatment. Along with this, the high cost of treatment has restricted its use in therapy. ${ }^{[22]}$

Another drug available for the treatment of leishmaniasis is paromomycin, an aminoglycosideaminocyclitol antibiotic, used for the first time in the treatment of leishmaniasis in 2002, in the form of paromomycin sulfate. ${ }^{[22]}$ It has been used to treat both forms of the disease, being used in parenteral formulations in the treatment of VL and in topical and parenteral formulations in the treatment of $\mathrm{CL}^{\left[{ }^{[6]}\right.}$ Since leishmaniasis mainly affects low-income populations, the low cost is one of the main advantages of paromomycin, although its parenteral administration makes it difficult for patients to adhere to treatment. $^{[18]}$ Paromomycin has high efficacy and excellent tolerability; however, side effects have also been reported, such as nephrotoxicity, ototoxicity, reversible increase in liver transaminases and pain at the injection site. ${ }^{[11,12]}$ Furthermore, although cases of resistance have not yet been reported, the develop- 
ment of in vitro resistance to paromomycin has already been reported in some species of Leishmania. ${ }^{[19]}$

Pentamidine is an aromatic diamidine used as a second-line medication in the treatment of leishmaniasis, being administered intramuscularly and its main advantage is short-term therapy. ${ }^{[14,19]}$ On the other hand, pentamidine presents serious adverse reactions, such as nephrotoxicity, cardiotoxicity, pancreatitis, hypoglycemia, leukopenia and anemia, which require constant monitoring of the patient. ${ }^{[12]}$ In addition, compared to other drugs, its effectiveness varies between Leishmania species, which has led to a reduction of its use in clinical treatment. ${ }^{[14,19]}$

Miltefosine is an alkylphosphocholine drug, originally developed as an anticancer agent, was the first oral drug approved for the treatment of $\mathrm{VL}$ and $\mathrm{CL}$. In general, it is a well-tolerated drug, but some adverse effects have already been reported, such as nephrotoxicity, gastrointestinal toxicity, and occasional liver toxicity, which makes it necessary to monitor the patient during treatment. Miltefosine also has teratogenic effects and abortive properties, which limits its use during pregnancy; in addition, its high half-life (about 1 week) can stimulate the development of resistance. ${ }^{[14,18]}$

Sitamaquine (8-aminoquinoline) is another medication that has the advantage of oral administration route. The main adverse effect observed was nephrotoxicity, and other effects were also seen, for example, vomiting, dyspepsia, glomerulonephritis, and headache. However, at doses well tolerated by the body, the drug showed low efficacy. The development of resistance has not yet been reported, although promastigote forms of $L$. donovani resistant to sitamaquine have been selected in the laboratory. ${ }^{[19]}$

\section{New Molecules with Potential for Treatment}

\subsection{In Vitro Studies}

The efficacy of treatment for leishmaniasis depend on a number of factors linked to the host, the environment, the type of drug administered and the parasite. ${ }^{[23]}$ The scientific community is always searching for new therapeutic strategies, and new low cost, less toxic and more effective compounds for the treatment of leishmaniasis. Thus, over the years, new molecules that inhibit the survival of Leishmania have been extensively investigated. Initially, to evaluate the potential of new drugs and their toxicity, laboratory studies are conducted as in vitro tests. These tests are generally used to evaluate cell toxicity and viability and have several advantages such as low cost, limited toxic waste, and controlled testing conditions. ${ }^{[24,25]}$ In this topic we describe the novel molecules which have shown potential antileishmanial effect in the in vitro tests.

Oliveira et al. reported the use of five thiazole derivatives of the thiazopyridines class (TP) and five of the thiazoacetylpyridines class (TAP) to evaluate in vitro activity against $L$. infantum. ${ }^{[26]}$ Thiazoles are a class of compounds that exhibit broad range of biological activity, including antitumor, antibacterial, and antiinflammatory activities. In this study, all the tested compounds inhibited the growth of promastigotes and presented low cytotoxicity. However, TAP-01, TAP04 and TAP-06 presented higher potential with lower $\mathrm{IC}_{50}$ values against amastigote $(0.99,0.43$ and $0.59 \mu \mathrm{M}$, respectively). TAP-04 (Figure 3, Structure 1, S1) showed better activity against both forms of the parasite, as well as lower cytotoxicity, and high selectivity index $(\mathrm{SI} /$ amastigote $=137.37)$ which is about seven times higher than the minimum established for a promising drug. The authors also investigated the possible intracellular targets, as well as the effect of the compounds on the parasite's cell membrane. The promastigotes without the addition of TAP-04 presented regular morphology, with a well-preserved nucleus, occupying the most central part of the cytoplasm, and chromatin associated with the internal nuclear membrane. After exposure to $1 / 2 \times \mathrm{IC} 50 \mathrm{TAP}-04$, the promastigotes presented swollen mitochondria with intense disorganization in the mitochondrial ridges, in addition to changes in the shape of the cell body, presenting rounded morphology and loss of the flagellum, together with loss of cell volume with intense wrinkles, suggesting cell death via apoptosis.

Chauhan et al. analyzed the leishmanicidal activity of trans-dibenzalacetone (DBA, S2), a low cost and easily synthesizable monoketone analog of curcumin. ${ }^{[27]}$ The authors observed an $\mathrm{IC}_{50}$ of $7.43 \pm$ $1.88 \mu \mathrm{g} / \mathrm{mL}$ and $17.80 \pm 1.42 \mu \mathrm{g} / \mathrm{mL}$ for amastigotes and promastigotes, respectively. The treatment of promastigotes with DBA caused morphological changes, such as cell reduction and rounding, in addition to extensive cytoplasmic vacuolization after $24 \mathrm{~h}$ of treatment. In addition, features associated with apoptosis such as cell arrest in the G0/G1 phase, depolarization of the mitochondrial membrane potential and an increase in cytosolic $\mathrm{Ca}^{2+}$ levels were observed. The authors also reported reduced levels of glutathione (GSH) in the treated cells compared to untreated cells. Kinetoplastids like Leishmania and Trypanosoma show an unusual form of glutathione 


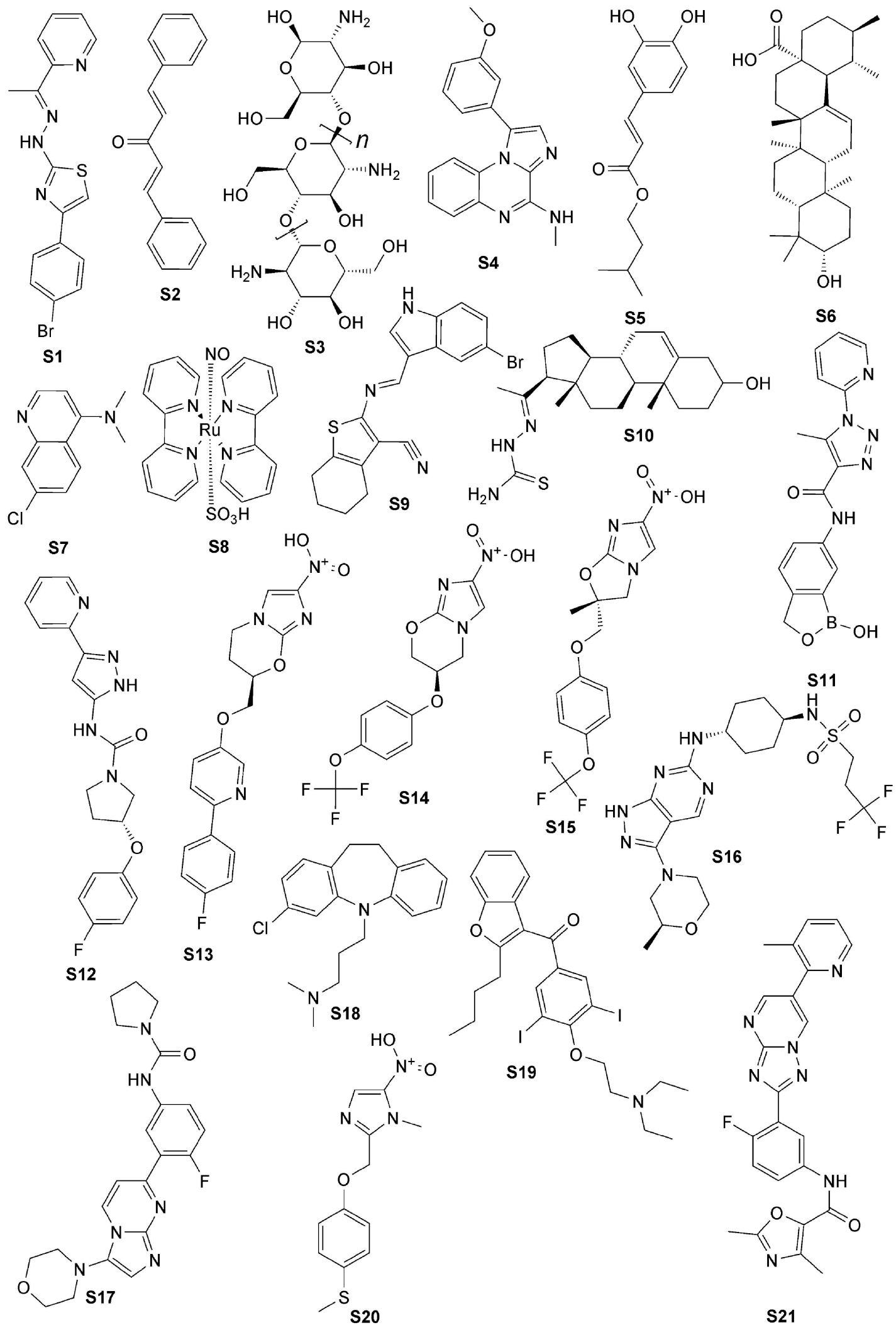

Figure 3. Chemical structures of the molecules cited in this work. S1-TAP-04, S2-DBA, S3-chitosan, S4-EAPB0503, S5-Isopentyl caffeate, S6-ursolic acid, S7-GF1059, S8-Ruthenium nitrosol complex, S9-SB-83, S10-Compound 8, S11-DNDI-6148, S12-DNDI-1044, S13-DNDI-0690, S14-DNDI-8219, S15-DNDI-VL-2098, S16-DDD853651/GSK3186899, S17-GSK3494245/DDD01305143, S18-Clomipramine, S19-Amiodarone, S20-Fexinidazole, S21-LXE408. 
(trypanothione) essential for the survival of the parasite and which is the target for the development of new drugs.

Chitosan (S3) is a biodegradable cationic polysaccharide, with proven antimicrobial, antileishmanial and immunostimulating activities. ${ }^{[28]}$ Previous studies have shown its in vitro antileishmanial activity with $\mathrm{IC}_{50}$ ranging from 70 to $240 \mu \mathrm{g} / \mathrm{mL}$ against both promastigotes and amastigotes forms of $L$. infantum, L. amazonensis and L. chagasi. ${ }^{[29-31]}$ Recently, Riezk et al. evaluated the in vitro antileishmanial activity of various forms of chitosan, including low, medium and high molecular weight chitosan and its derivatives, against extracellular promastigotes and intracellular amastigotes of L. major and L. mexicana. ${ }^{[32]}$ In this study, the authors demonstrated for the first time a $\mathrm{pH}$ dependent antileishmanial activity of chitosan and its derivatives, which may justify the great variability of the antileishmanial activity of this compound in the literature. The authors reported minimal cytotoxicity against human squamous carcinoma cells (KB cells), with $\mathrm{CC}_{50}$ of $750 \mu \mathrm{g} / \mathrm{mL}$ at $\mathrm{pH} 7.5$ or 6.5 . Chitosan and its derivatives were approximately 7 to 20 times more active at $\mathrm{pH} 6.5$ than at $\mathrm{pH} 7.5$, with high molecular weight chitosan being the most potent (except carboxymethyl chitosan). This increased chitosan activity at a lower $\mathrm{pH}$ of 6.5 may be due to its greater ionization. It is believed that the positive charge can increase the antimicrobial activity of chitosan due to the interaction with the negatively charged microbial membrane. The authors concluded that chitosan and its water-soluble derivatives have antileishmanial activity against $L$. major and $L$. mexicana promastigotes and amastigotes in a pH-dependent manner and that their antileishmanial activity is related to the direct uptake of chitosan in the parasitophore vacuole by pinocytosis.

El Hajj et al. characterized the effect of imiquimod, an immunomodulatory drug, against L. tropica and L. major, and elucidated the molecular mechanisms that dictate antileishmanial efficacy against both the strains. ${ }^{[33]}$ In addition, they also investigated the potency and molecular mechanisms of an imiquimod analog, EAPB0503 (S4), against these two strains. Both drugs reduced the replication of amastigotes, however, the compound EAPB0503 was more potent, particularly against amastigote forms of $L$. tropica. Tolllike receptor 7 (TLR7) was found to be positively regulated, mainly by imiquimod, and to a lesser extent by EAPB0503. Furthermore, the drugs activated the canonical route of NF-kB, generating an immune response and the superregulation of $\mathrm{i}$-NOS in infected macrophages. The authors conclude that imiquimod and EAPB0503 could be strong candidates for the treatment of $L$. tropica.

Our group has been studying isopentyl caffeate (ICaf, S5) for its antileishmanial activity. ICaf is derived from caffeic acid and has shown good activity against the promastigote and amastigote forms of cutaneous (L. amazonensis) and visceral (L.chagasi) leishmaniasis. ${ }^{[34,35]}$ The hydrophobic nature of ICaf limit its bioavailability. To overcome its low solubility an inclusion complex of ICaf in $\beta$-cyclodextrin ( $\beta$-CD) was developed. The ICaf $/ \beta-C D$ with improved solubility retained high antileishmanial activity in vitro $(<10 \mu \mathrm{g} /$ $\mathrm{mL}$ ) against both $L$. amazonensis and $L$. chagasi.

\subsection{In Vivo Studies}

The safety assessment of new molecules requires animal studies before advancing for clinical trials. These in vivo studies aim to obtain information on several aspects of the new molecule with respect to its functioning in a biological system, before its testing in humans. ${ }^{[36,37]}$ The selection of the animal model to be used is one of the most important steps, since the choice of the species will give the best correlation with the human trials. Differences in the gut, enzyme activity, circulatory system, or other characteristics make certain models more suitable than others for a given goal. For example, differences in metabolism between two species will affect both toxicology and efficacy of the substance. ${ }^{[37,38]}$ It is also important to mention that animal models of human diseases not only facilitate compound selection and early assessment of the mechanism of action, but also provide a better understanding of the therapeutic index and therefore improve clinical-dose selection for human trials. ${ }^{[39]}$

Bilbao et al. evaluated the efficacy of ursolic acid $(\mathrm{UA}, \mathrm{S6}){ }_{,}{ }^{[40]}$ a multifunctional triterpenoid with proven antitumor, antioxidant, antimicrobial and antifungal activities. $^{[41,42]}$ In this study, in vivo UA activity was evaluated in both acute and chronic models of VL. In addition, topical formulations were also developed, and their efficacy was tested in a chronic model of CL. The authors first reported the antileishmanial activity in vitro against amastigotes of L.amazonensis and $L$. infantum, being six and three times greater than the promastigotes, respectively. Also, the selectivity index of UA was found to be higher (three and eight-fold higher depending on the strain) compared to miltefosine. The authors explained greater activity of UA observed in the amastigotes compared to the promas- 
tigotes by their dual mode of action. UA showed activity not only on the parasite, but also stimulated the immunological response of the host cell, mainly by increasing NO production in macrophages. In acute and chronic model of $L$. infantum (VL), UA was tested via intraperitoneal route administering $5 \mathrm{mg} / \mathrm{kg}$ daily for seven consecutive days. A $99,83 \%$ and $99,78 \%$ reduction in the parasitic load was observed in the spleen and liver in the acute model, while a $58 \%$ and $79 \%$ reduction in the number of parasites in the spleen and liver was observed in the chronic model. In the chronic model for $\mathrm{CL}$, the lesion progression decreased by approximately $42 \%$ and $50 \%$ (at weeks 10 and 15) during topical administration of $A U$ ointment $(0,2 \%)$ for 28 days. However, it can be noted that the parasites were not fully eradicated after topical administration, since inflammation increased at week 15. AU was shown to modulate the Th1 response in the immune system, resulting in the death of the parasite, by increasing of IFN- $\gamma$ and decreased IL-4. Furthermore, no evident signs of toxicity were observed in the animals, which suggests that ursolic acid was well tolerated in the administered dose, making it a promising candidate against visceral and cutaneous leishmaniasis.

In 2019, in an in vitro and in vivo study against L. infantum and L. amazonensis, Soyer et al. evaluated the activity of a chloroquinoline derivative (GF1059, S7) by means of cytotoxicity analysis in macrophages, hemolytic potential in human red blood cells, and efficacy of the compound against infected macrophages. ${ }^{[43]}$ The data showed $I C_{50}$ of $4.23 \pm 0.34$ and $7.53 \pm 1.04 \mu \mathrm{M}$ against promastigotes, and $4.73 \pm$ 1.09 and $8.75 \pm 1.10 \mu \mathrm{M}$ against amastigotes of $L$. infantum and L. amazonensis, respectively. Macrophages treated with GF1059 prior to infection with L. amazonensis and L. infantum showed $79 \%$ and $80 \%$ reduced infection. The authors also reported a reduction in the parasitic load in infected tissue $(50 \%)$, spleen $(29 \%)$, liver (50\%) and lymph node (59\%). GF1059 showed low toxicity and did not induce hemolysis in human red blood cells. The compound also resulted in decreased membrane potential, increased autophagic vacuolos and excessive production of reactive oxygen species, all of which were probably responsible for causing death of the parasite. In addition, phosphatidylserine markers and membrane integrity were also evaluated, and, despite mitochondrial damage, the results did not show any type of alteration in these evaluations.

Nascimento et al. evaluated the leishmanicidal potential of the ruthenium nitrosol complex (RuNO,
S8) against $L$. brasiliensis by means of an in vitro (mice dermal fibroblasts) and an in vivo study (using hamsters). ${ }^{[41]}$ The nitrosyl ruthenium complexes have proven biological activity, such as antiparasitic, antiangiogenic, analgesic, gastroprotective and cerebral neuroprotection. ${ }^{[44-49]}$ In this study, the authors showed that RuNo had no cytotoxic effect on dermal fibroblasts at any of the concentrations tested. In the in vitro tests, $4 \mathrm{~h}$ treatment with RuNO complex $(100 \mu \mathrm{M})$ could completely reduce the number of infected cells. Similarly, in the hamster model, after the first week it was possible to observe a reduction in lesion size. The number of parasite decreased $99.9 \%$ with $300 \mu \mathrm{g} / \mathrm{kg} /$ day of the compound. Despite good leishmanicidal action, this study did not report any possible mechanism of action, however, the authors discuss that NO is one of the crucial molecules in the control of the parasitic load during the development of cutaneous leishmaniasis. Ruthenium complexes have shown to function as NO donor and associated with antileishmanial activity by NO release and intracellular elimination of the parasite. ${ }^{[44,50]}$

Rodrigues et al. analyzed the acute toxicity, genotoxicity and oral efficacy of SB-83 (S9) (a 2-aminotiophene derivative) in vivo against $L$. amazonensis. ${ }^{[51]}$ Thiophene belong to a group of aromatic heterocyclic compounds and present biological properties such as anti-inflammatory, antitumor, antinociceptive, anticonvulsant and antiarrhythmic activities. ${ }^{[52]}$ The authors demonstrated that in the ninth week of the treatment with SB-83 $(200 \mathrm{mg} / \mathrm{kg})$, there was a reduction in lesion size by $52.47 \% \pm 5.32$. The parasitic load was reduced in the lymph node $(42.57 \% \pm 3.14)$ and in the spleen (100\%). Th1 and Th2 responses were analyzed by measuring IFN- $\gamma$ and IL-10 levels, respectively. An increase in IFN- $\gamma$ (5.67 times) was observed without any alteration in the IL-10 levels. The increase in IFN- $\gamma$ confirms the immunomodulatory activity of SB-83 because the production of IFN- $\gamma$ by Th1 lymphocytes is one of the main activators of macrophages responsible for the control of Leishmania. The SB-83 toxicological study concluded that there were no changes in biochemical and hematological parameters, suggesting the safety of the compound. The genotoxicity was analyzed via micronucleus tests, which assesses the ability of a substance to cause clastogenicity and aneugenicity. The results showed that SB-83 did not cause an increase in the number of micronuclei in the peripheral blood of the treated animals, suggesting absence of genotoxic effect.

Aguilera et al. evaluated the potential of a new class of steroids against L.infantum and 
L. amazonensis. ${ }^{[33]}$ The authors synthesized and chemically characterized a series of nineteen steroidal arylideneketones and thiazolidenehydrazines and explored biological activity against L. infantum and L. amazonensis (both in vitro and in vivo), in addition to analyzing the genotoxicity and acute toxicity in vitro and in mice. The data showed that compound 8 (ID 1260 , a steroidal thiosemicarbazone compound) (S10) was most active, with an $\mathrm{IC}_{50}$ of less than $200 \mathrm{nM}$ in human macrophages infected with $L$. infantum. In the genotoxicity test, compound 8 used in a single dose of $150 \mathrm{mg} / \mathrm{kg}$ did not induce chromatin damage in bone marrow cells, thus not presenting toxicity.

Recently, Drugs for Neglected Diseases initiative (DNDi) reported three classes of lead-derived chemicals: benzoxaboroles (S11), aminopyrazoles (S12) and nitroimidazoles (S13, S14, and S15), which have great antileishmanial activity. These compounds have shown favorable pharmacokinetic profiles ensuring bioavailability after oral administration and high levels of activity against murine visceral leishmaniasis. ${ }^{[54]}$ Van Bocxlaer et al. evaluated the effectiveness of these compounds in the in vitro and in vivo models for cutaneous leishmaniasis. ${ }^{[55]}$ The in vitro activity of the compounds was evaluated against intracellular amastigote forms of L. major, L. aethiopica, L. amazonensis, L. panamensis, L. mexicana and L. tropica. Drugs that demonstrated potent activity $\left(\mathrm{EC}_{50}<5 \mu \mathrm{M}\right)$ against at least 4 of 6 species were evaluated in vivo in mouse models. The animals received treatment for 5 or 10 days with oral or topical formulations. Due to the cutaneous form of the disease, the efficacy was expressed by the size of the lesion and the parasitic load. The results of this study showed that all the drugs tested showed marked levels of potency against the species of the Old and New World. In the in vitro peritoneal assay, the aminopyrazoles showed the most potent antileishmanial activity with $\mathrm{EC}_{50}$ values in the nanomolar range (like amphotericin $\mathrm{B}$ ). It is noteworthy that 3 nitroimidazoles, 1 benzoxaborole and 3 aminopyrazoles showed consistent and potent activity against a variety of Leishmania species. Moreover, all the compounds were well tolerated with no obvious signs of toxicity observed in mice after oral administration. In some cases, there was a complete reduction in the size of the lesion, that was correlated with the reduction of the parasite load and its effectiveness was dependent on the dose and duration of treatment.

Wyllie et al. reported GSK3186899/DDD853651 (S16), a pyrazolopyrimidine derived from trifluoropropyl sulfonamide. ${ }^{[56]}$ This compound was selected as a preclinical candidate based on the general properties of the molecule (potency, efficacy in the mouse model, pharmacokinetics, and safety profile) against VL. In addition to its favorable physico-chemical and pharmacokinetic properties, it presented adequate toxicological results for its use in clinical trials. Detailed studies on the action indicated that the compounds in this series act mainly by inhibiting the parasite cdc- 2 related kinase 12 (CRK12), that is essential in the cell cycle of the parasite, ${ }^{[57]}$ thus is also a potential pharmacological target for visceral leishmaniasis. Treatment with this compound resulted in the accumulation of parasitic cells in the $G 1$ and $G 2$ phases of the cell cycle together with a decrease in the proportion of cells in the $S$ phase, suggesting a cell cycle arrest in the $G 1 / S$ and $G 2$ phases. ${ }^{[56]}$ In another study carried out by the same research group, the compound GSK3494245/DDD01305143 (S17) (belonging to the same series), also demonstrated potential to treat leishmaniasis. The compound was shown to have promising pharmacokinetic properties and in vivo efficacy in the mouse model when compared to miltefosine. Furthermore, it was confirmed that it worked mainly by inhibiting chymotrypsin-like activity catalyzed by the $\beta 5$ subunit of the L.donovani proteasome. $^{[58]}$

During a study to discover anti-tuberculosis agents, Thompson et al. discovered a new class of 7-substituted oxazines, with potent antileishmanial activity. ${ }^{[59]}$ After identification and susceptible efficacy tests, seeking better solubility and safety, the bioisosteres formed by replacing a phenyl with pyridine or pyrimidine showed improved solubility and potency, while more hydrophilic lateral chains reduced the activity against visceral leishmaniosis. Evaluation of a representative set of nine racemic compounds in the visceral leishmaniasis (L.donovani) mouse model showed phenylpyridines 79 (or R form 71) and 93 (or R form 94) as the most effective, with compound 93 showing $50 \%$ inhibition at $1.56 \mathrm{mg} / \mathrm{kg}$. In the chronic infection (L. infantum) hamster model, compound 71 (at $12.5 \mathrm{mg} / \mathrm{kg}$ ) achieved reductions exceeding $99 \%$ in parasite burden for all target organs. Subsequent synthesis and assessment of the enantiomers of both lead compounds identified the $\mathrm{R}$ forms as superior, and in the case of 71 , this outcome was reinforced by excellent results in the $L$. infantum hamster model and favorable pharmacokinetics data in the hamster and mouse. 


\section{Drug Repurposing}

Currently, the need to obtain a drug more quickly and with lower cost is essential for both the pharmaceutical industry and the population. Thus, the repurposing of drugs has been gaining space within this market, allowing reduction in expenses, and at the same time optimizing the release time by health regulatory agencies. ${ }^{[60]}$ The reuse of drugs is neither uncommon nor less profitable for companies and, given the global health situation, it presents a reliable and safe option to design an efficient therapy. ${ }^{[61]}$ In the United States, for example, drug reuse accounted for about $30 \%$ of drug approvals in the recent years. ${ }^{[62]}$ Despite having some limitations, the reuse of clinical trials represent a good strategy, because it facilitates the reuse of drugs already approved, thus reducing the time and bureaucracy to reach the market. ${ }^{[63]}$ Drug repurposing helps to develop new therapies with drugs that are already used clinically and whose tests with patients are already known. ${ }^{[64]}$

Using this strategy, Rodrigues et al. demonstrated that clomipramine (S18) had potential against L. amazonensis. ${ }^{[65]}$ This medication is a tricyclic antidepressant used to treat psychiatric disorders, such as obsessive-compulsive disorder. ${ }^{[6]]}$ In this study, the parasites were incubated in the presence or absence of different concentrations of clomipramine for $72 \mathrm{~h}$. The results demonstrated that the antidepressant was a selective inhibitor of the extracellular and intracellular forms of the parasite, with $\mathrm{IC}_{50}$ of $8.31 \pm$ $3.29 \mu \mathrm{M}$ and $\mathrm{IC}_{90}$ of $21.58 \pm 3.44 \mu \mathrm{M}$ against promastigotes. There was also greater selectivity against parasites than host cells, with a selectivity index of 11.72 for amastigotes and 21.81 for promastigotes. Clomipramine has been reported to act via mitochondrial pathway in L.amazonensis, in addition to inhibiting the function of the trypanothione reductase. ${ }^{[67]}$ In this study, Rodrigues et al. showed that both in promastigotes and amastigotes, the drug induced oxidative stress by increasing the levels of reactive oxygen species and $\mathrm{H}_{2} \mathrm{O}_{2} \cdot{ }^{[65]}$ In promastigotes, the reduction in cell size, membrane shrinkage, DNA fragmentation and exposure to phosphatidylserine, suggests cell death via apoptosis. Despite changes in mitochondrial physiology, ATP levels were not affected in promastigotes and amastigotes, and no loss of membrane integrity was observed.

Bemani et al. evaluated amiodarone (S19) (a antiarrhythmic class III drug) against L. major. ${ }^{[68]}$ The authors reported good potential in both in vitro and in vivo analyzes, through tests related to wound healing, immune response, activities of antioxidant enzymes and malondialdehyde (MDA), ferric reducing ability of plasma (FRAP) and adiponectin levels in infected mice. An $\mathrm{IC}_{50}$ of $1 \mu \mathrm{M}$ (promastigotes) and $0.7 \mu \mathrm{M}$ (amastigotes) was observed. There was a decrease in the size of lesions treated with amiodarone $(40 \mathrm{mg} / \mathrm{kg})$ after 12 days. The number of macrophages and neutrophils were lower in the lesions of animals treated with the drug, so that they demonstrated adequate formation of granulation tissue, well vascularized and infiltrated by fibroblasts and mature fibrocytes, different from untreated groups that presented necrosis, infiltration by polymorphonuclear cells, macrophages, and lymphocytes, as well as small amounts of fibrous connective tissue with few newly regenerated blood vessels. Greater angiogenesis was observed in lesions treated with amiodarone, probably due to the decrease of levels of tumor necrosis factor- $\alpha$ (TNF- $\alpha$ ) and interleukin cytokines such as IL-6. Although the presence of TNF- $\alpha$ has an advantage over the host's defense mechanism against pathogens, an excessive release results in impaired healing. Moreover, it is necessary to have a balance in the release of IL- 6 , since this interleukin mediates the transition from acute to chronic inflammation. Despite the potential of amiodarone, total wound healing was not observed. The parasitic load decreased after 28 days of treatment. There was no significant increase in adiponectin and MDA, important in the wound healing process. Amiodarone caused the formation of autophagosomes, and the presence of lipid bodies and vacuoles in the cytoplasm could be observed. However, the long duration or the administration of high doses of amiodarone have been reported to cause toxicity in several organs. ${ }^{[69-73]}$

Morais-Teixeira et al. evaluated fexinidazole (S20) in vitro and in vivo studies against L. infantum, L. amazonensis, L. braziliensis and L. guyanensis. ${ }^{[7]}$ Fexinidazole is a nitroimidazole that was developed in the 1980s against trypanosomes. The authors observed that after 23 days of oral treatment with fexinidazole (200 and $300 \mathrm{mg} / \mathrm{kg} /$ day), $80 \%$ of the animals infected with L.amazonensis presented complete healing of the lesion. On the other hand, $100 \%$ of the animals infected with L.guyanensis and treated orally with fexinidazole $(200 \mathrm{mg} / \mathrm{kg} /$ day $)$ presented a completely healed lesion with $98.4 \%$ reduction in the alterations observed in the liver and no significant loss of animal body weight. Fexinidazole thus presented good potential without toxicity in spite of high doses required for the treatment in the animal model. 


\section{Clinical Trials}

Leishmaniasis is an important neglected tropical disease, despite it being one of the six most frequent parasitic diseases in the world. Very few advances have been made for its treatment, with the same pharmacological treatments in use since 1940s. The drugs currently in use for the treatment are associated with low therapeutic indices and significant side effects. ${ }^{[75]}$ Thus, the search for more effective therapies that present fewer side effects for the treatment of leishmaniasis is necessary.

Vast majority of clinical studies in process involve improving the efficacy of drugs already in use for the treatment of leishmaniasis such as pentavalent antimonials (sodium sybogluconate and meglumine antimoniate), amphotericin $B$ deoxycholate, lipid formulations of amphotericin B (e.g., AmBisome ${ }^{@}, A B L C$, Amphocil ${ }^{\circledR}$, miltefosine, paromycin and pentamidine, ${ }^{[76]}$ and are related, more specifically, to improve the dose regimen. There are very few potential new drugs in the clinical phase for the treatment of leishmaniasis.

Four drugs (DNDI-0690, DNDI-6148, LXE408 and GSK3494245) in which preclinical development has already been completed have started the clinical studies since 2019. DNDI-0690 belongs to the class of nitroimidazole (a class known for its broad spectrum of antiparasitic properties) which was developed from fexinidazole (structural improvement). ${ }^{[77,78]}$ The preclinical development of DNDI-0690 (S13) has already been completed after observing that it is highly effective in mice and hamsters VL models. ${ }^{[79,80]}$ Its nitro group is believed to be bioactivated by the enzyme nitroreductase NTR2 in Leishmania parasites, ${ }^{[81]}$ leading to reactive intermediates that kill the parasite. Under the title "Single Oral Dose Escalation Study of DNDI0690 in Healthy Subjects", the project was approved for the phase I clinical studies (NIH, 2019; identifying number: NCT03929016).

Another drug in clinical trial for the treatment of Leishmania is DNDI-6148 (S11) belonging to the class of oxaborole. It was observed that after 5 to 10 days of treatment, this drug could reduce high levels of parasitic load in VL mice and hamster models. Its mechanism of action is not yet well understood, but it is thought to be distinct from the antileishmanial therapies currently used, since it maintains activity against strains resistant to these drugs. The pharmacological safety studies for this drug have already been completed. ${ }^{[80,82,83]}$ DNDI-6148 was approved at the end of 2018 for phase I clinical studies, with the objective to evaluate its safety and tolerance in increasing single doses $(10 \mathrm{mg}, 20 \mathrm{mg}, 40 \mathrm{mg}, 80 \mathrm{mg}$, $160 \mathrm{mg}, 260 \mathrm{mg}, 380 \mathrm{mg}$, and $500 \mathrm{mg}$ ) in healthy male volunteers compared to the placebo group. In addition, the phase I study is also being used to study the pharmacokinetic and pharmacodynamic properties of DNDI-6148. ${ }^{[84]}$

Nagle et al. showed that the chemical optimization of GNF6702 successfully led to the compound LXE408 (S21) which, when administered orally, demonstrated excellent efficacy in mice model with a good safety profile. ${ }^{[85]}$ Based on these positive results, LXE408 was approved for clinical trials. In February 2020, the Novartis pharmaceutical industry and the Drugs for Neglected Diseases initiative (DNDi), a non-profit research and development (R\&D) organization signed a collaboration and license agreement to jointly develop the LXE408. In this agreement, Novartis was responsible for completing phase I clinical trials. While DNDi was responsible for Phase II and Phase III trials, with the first Phase II study scheduled to begin in early 2021 in India, with additional testing planned to take place in East Africa. ${ }^{[86]}$

GSK3494245 (S17), which was initially identified as a proteasome inhibitor, is a candidate for the treatment of leishmaniasis due to its potential preclinical leishmanicidal effect, in addition to demonstrating a desirable safety profile and pharmacokinetics. ${ }^{[87]}$ The phase I clinical study titled "Safety, Tolerability and Pharmacokinetics Investigation of GSK3494245 in Healthy Participants" began in September 2020 is a randomized, double-blind, placebo-controlled study to evaluate in humans the safety, tolerability and pharmacokinetics of single doses of GSK3494245 in healthy participants, and consists of 3 cohorts (cohorts 1, 2 and 3), conducted in sequential order. ${ }^{[88]}$ Table 1 summarizes the novel molecules described in this study. Despite efforts, the number of drugs reaching human trials is still extremely low.

\section{Future Perspectives}

Currently, there is no fully effective therapy for leishmaniasis. Treatment is based on chemotherapy; however, most drugs are expensive and have toxic side effects. Although advances are limited, the scientific community has been searching for new strategies and compounds that have little or no toxic effect in relation to the current treatment, such as the use of immunotherapies, nanoparticles, vaccines, and substances for topical use (Figure 4). The development 
Table 1. Recent pre-clinical and clinical studies, described for leishmaniasis.

\begin{tabular}{|c|c|c|c|}
\hline Drug & Tested Species & Study Phase & Refs. \\
\hline Thiazopyridine (TP) & L. infantum & Pre-clinical (in vitro) & [26] \\
\hline \multicolumn{4}{|l|}{ Thiazoacetylpyridine (TAP) } \\
\hline trans-dibenzalacetone (DBA) & $\begin{array}{l}\text { L. infantum } \\
\text { L. amazonensis } \\
\text { L. chagasi }\end{array}$ & Pre-clinical (in vitro) & [27] \\
\hline Imiquimod & $\begin{array}{l}\text { L. tropica } \\
\text { L. major }\end{array}$ & Pre-clinical (in vitro) & [89] \\
\hline Ursolic acid (UA) & $\begin{array}{l}\text { L. amazonensis } \\
\text { L. infantum }\end{array}$ & Pre-clinical (in vivo) & [40] \\
\hline Chloroquinoline derivative (GF1059) & $\begin{array}{l}\text { L. infantum } \\
\text { L. amazonensis }\end{array}$ & Pre-clinical (in vivo) & [43] \\
\hline Ruthenium nitrosyl complex (RuNO) & L. brasiliensis & Pre-clinical (in vitro and in vivo) & [41] \\
\hline SB-83 (a 2-amino- thiophene derivative) & L. amazonenses & Pre-clinical (in vivo) & [51] \\
\hline $\begin{array}{l}\text { Steroidal arylideneketones } \\
\text { and thiazolidenehydrazines }\end{array}$ & $\begin{array}{l}\text { L. infantum } \\
\text { L. amazonenses }\end{array}$ & Pre-clinical (in vitro and in vivo) & [53] \\
\hline $\begin{array}{l}\text { Benzoxaboroles, Aminopyrazoles } \\
\text { and Nitroimidazoles }\end{array}$ & $\begin{array}{l}\text { L. major } \\
\text { L. aethiopica } \\
\text { L. amazonensis } \\
\text { L. panamensis } \\
\text { L. mexicana } \\
\text { L. tropica }\end{array}$ & Pre-clinical (in vitro and in vivo) & [80] \\
\hline DDD853651/GSK3186899 & L. donovani & Pre-clinical (in vivo) & [56] \\
\hline $\begin{array}{l}\text { 6-nitro-2,3-dihydroimidazo-[2,1-b][1,3]-thiazoles } \\
\text { and related -oxazoles }\end{array}$ & $\begin{array}{l}\text { L. donovani } \\
\text { L. infantum }\end{array}$ & Pre-clinical (in vitro) & [59] \\
\hline Clomipramine & L. amazonensis & Pre-clinical (in vivo) & [51] \\
\hline Voriconazole & L. major & Pre-clinical (in vitro and in vivo) & [90] \\
\hline Fexinidazole & $\begin{array}{l}\text { L. chagasi } \\
\text { L. amazonensis } \\
\text { L. braziliensis } \\
\text { L. guyanensis }\end{array}$ & Pre-clinical (in vitro and in vivo) & [74] \\
\hline DNDI-0690 & $\begin{array}{l}\text { L. mexicana } \\
\text { L. major }\end{array}$ & Phase 1 clinical trials & {$[80]$} \\
\hline DNDI-6148 & $\begin{array}{l}\text { L. major } \\
\text { L. donovani }\end{array}$ & Phase 1 clinical trials & [84] \\
\hline LXE408 & L. donovani & Phase 1 has been completed & [85] \\
\hline GSK3494245 & L. donovani & Phase 1 clinical trials & [87] \\
\hline
\end{tabular}

process normally occurs through the Target Product Profile, a planning tool that describes the result of research and development of desired drugs and allows the selection, progression, and management according to well-defined decision matrices. Accordingly, some parameters are defined for the choice of the Preclinical Target Candidate Profile, in which the physicochemical, pharmacokinetic, safety and formulation properties of the selected compound are described for pre-clinical development, functioning as a prologue for clinical studies.

Studies have highlighted the use of nanoparticles to reduce drug resistance. The use of drug liberation systems based on nanotechnology, loaded with antileishmania agents, can protect the drugs against oxidation reduction and enzymatic reactions, increase bioavailability through controlled drug release and increase efficacy. The scientific community has also investigated the drug-immunotherapy relationship to optimize the treatment of leishmaniasis. Despite promising results, this treatment cannot be recommended due to its high cost. Topical therapies have proven to be less toxic option compared to systemic options, however, limited to less severe forms of treatment, without the risk of dissemination and development of the disease. These methods are recommended for individuals with few and small injuries, more effective in infections by L. mexicana or L. major. Synergistic drug combinations are another option for a more effective treatment, as combinatorial therapies are also relatively cheaper and present a minimal risk to patients due to the access to previous 


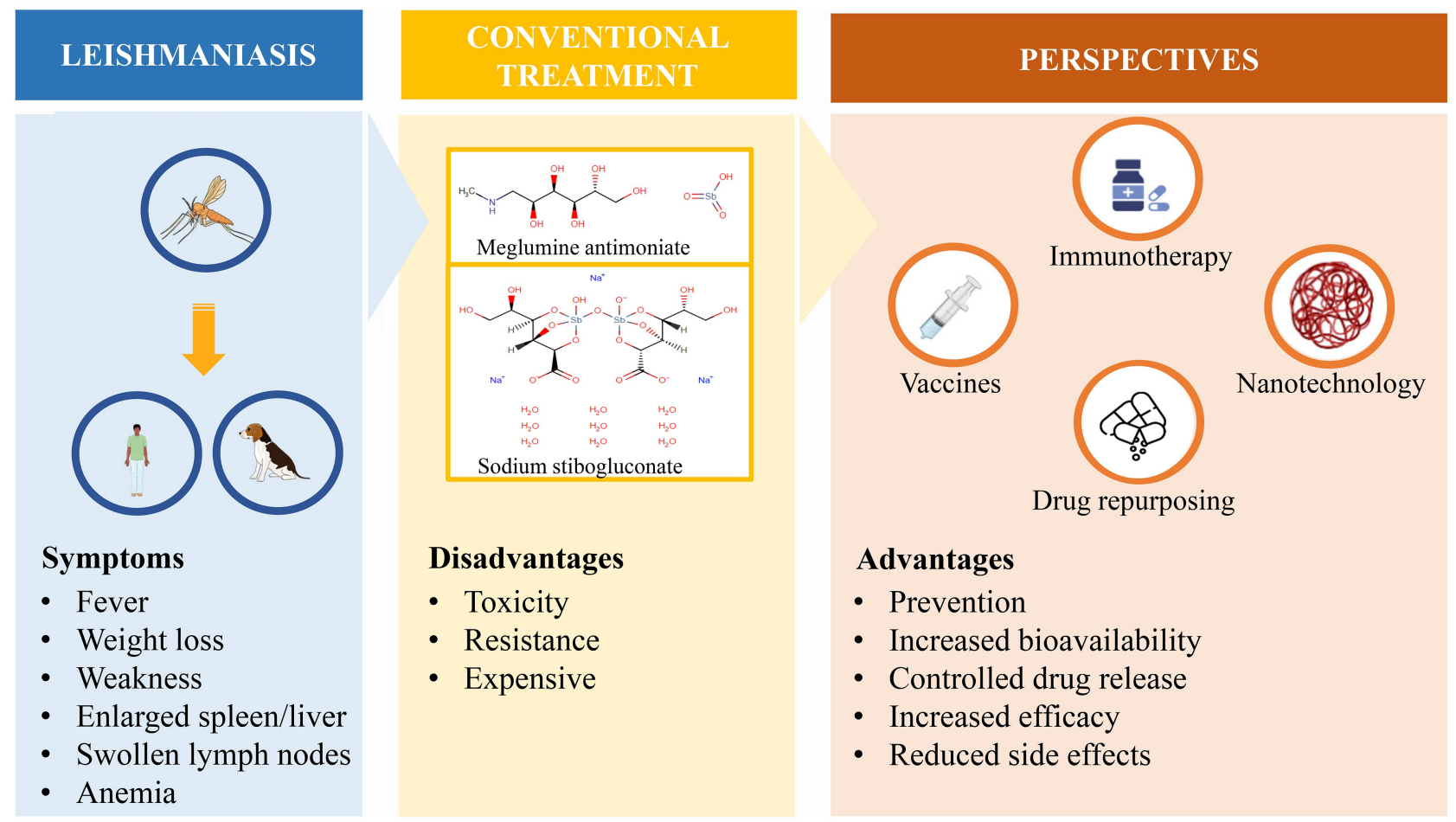

Figure 4. New strategies to overcome the disadvantages associated with the current treatment.

pharmacological, safety and toxicological data. Vaccines have shown excellent results, especially in prevention, however, they are not widely researched and developed. It is believed that its commercialization is less lucrative, when compared to the development of drugs, making research inclined to immunotherapeutic formulations. It is also worth to mention that, due to the complexity of the immune responses necessary for protection against Leishmania, the development of vaccines has been a challenging task. Finally, the control of this disease is done exclusively with medications and follows the therapeutic protocol of each country, respecting its regionality and the guidelines of the World Health Organization. The scarcity of new anti-leishmania agents highlights the need to search for newer molecules with antileishmania activity, mainly due to the emergence of strains resistant, complications created due to coinfections and toxicity shown by the conventional drugs. Thus, although there have been countless advances, treatment against leishmaniasis is still considered a challenge and the search for ideal treatments continue.

\section{Acknowledgments}

This research was funded by Conselho Nacional de Desenvolvimento Científico e Tecnológico for the Scientific grants (CNPq 301964/2019-0 Chamada No. 06/2019, Chamada CNPq No. 01/2019) and Portuguese Science and Technology Foundation, Ministry of Science and Education (FCT/MEC) through the sponsorship of the project M-ERA-NET-0004/2015-PAIRED (strategic fund), co-financed by FEDER, under the Partnership Agreement PT2020. We would like to thank Tiago Branquinho Oliveira for the help provided in drawing Figure 3.

\section{Author Contribution Statement}

WS, SSCO, MHR, ALSS and SSD contributed for the conceptualization, methodology, validation, formal analysis, and investigation, and writing - original draft preparation. EBS, PS and SJ contributed for the methodology, supervision, writing - review and editing, project administration, resources, and funding acquisition. All authors have made a substantial contribution to the work. All authors have read and agreed to the published version of the manuscript. 


\section{References}

[1] S. S. Oliveira, C. S. Ferreira, M. H. Branquinha, A. L. Santos, M. V. Chaud, S. Jain, J. C. Cardoso, A. B. Kovačević, E. B. Souto, P. Severino, 'Overcoming multi-resistant leishmania treatment by nanoencapsulation of potent antimicrobials', J. Chem. Technol. Biotechnol. 2021, 96, 2123-2140.

[2] H. Akuffo, C. Costa, J. van Griensven, S. Burza, J. Moreno, M. Herrero, 'New insights into leishmaniasis in the immunosuppressed', PLoS Neglected Trop. Dis. 2018, 12, e0006375.

[3] E. B. Souto, J. Dias-Ferreira, S. A. Craveiro, P. Severino, E. Sanchez-Lopez, M. L. Garcia, A. M. Silva, S. B. Souto, S. Mahant, 'Therapeutic Interventions for Countering Leishmaniasis and Chagas's Disease: From Traditional Sources to Nanotechnological Systems', Pathogenesis 2019, 8.

[4] N. E. Aronson, 'Addressing a clinical challenge: Guidelines for the diagnosis and treatment of leishmaniasis', BMC Med. 2017, 15, 1-3.

[5] E. Torres-Guerrero, M. R. Quintanilla-Cedillo, J. Ruiz-Esmenjaud, R. Arenas, 'Leishmaniasis: a review', F1000Research 2017, 6 .

[6] N. Varma, S. Naseem, 'Hematologic changes in visceral leishmaniasis/kala azar', Ind. J. Hem. Blood Transf. 2010, 26, 78-82.

[7] WHO, Vol. 2021, https://www.who.int/en/news-room/factsheets/detail/leishmaniasis, 2020.

[8] A. Akhlagh, A. Salehzadeh, A. H. Zahirnia, B. Davari, '10-year trends in epidemiology, diagnosis, and treatment of cutaneous Leishmaniasis in Hamadan Province, West of Iran (2007-2016)', Frontiers Pub. Health 2019, 7, 27.

[9] J. Sunter, K. Gull, 'Shape, form, function and Leishmania pathogenicity: from textbook descriptions to biological understanding', Open Biol. 2017, 7, 170165.

[10] P. A. Bates, 'Transmission of Leishmania metacyclic promastigotes by phlebotomine sand flies', Int. J. Parasitol. 2007, 37, 1097-1106.

[11] A. Dostálová, P. Volf, 'Leishmania development in sand flies: parasite-vector interactions overview', Parasites \& Vectors 2012, 5, 1- 12.

[12] B.S. Mcgwire, A. Satoskar, 'Leishmaniasis: clinical syndromes and treatment', Q. J. Med. 2014, 107, 7-14.

[13] S. Jain, W. Santana, S. S. Dolabella, A. L. S. Santos, E. B. Souto, P. Severino, 'Are Nanobiosensors an Improved Solution for Diagnosis of Leishmania?' Pharmaceutica 2021, 13, 491.

[14] J. P. B. de Menezes, C. E. S. Guedes, A. L. d. O. A. Petersen, D. B. M. Fraga, P. S. T. Veras, 'Advances in development of new treatment for leishmaniasis', BioMed Res. Int. 2015, 2015. Article ID 815023.

[15] S. Sundar, J. Chakravarty, D. Agarwal, M. Rai, H. W. Murray, 'Single-dose liposomal amphotericin B for visceral leishmaniasis in India', New Eng. J. Med. 2010, 362, 504-512.

[16] N. M. Ikeogu, G. N. Akaluka, C. A. Edechi, E. S. Salako, C. Onyilagha, A. F. Barazandeh, J. E. Uzonna, 'Leishmania immunity: advancing immunotherapy and vaccine development', Microorganisms 2020, 8, 1201.

[17] E. Diro, L. Lynen, K. Ritmeijer, M. Boelaert, A. Hailu, J. van Griensven, 'Visceral leishmaniasis and HIV coinfection in East Africa', PLoS Neglected Trop. Dis. 2014, 8, e2869.

[18] J. Chakravarty, S. Sundar, 'Drug resistance in leishmaniasis', J. Global Infectious Diseases 2010, 2, 167.
[19] N. Singh, M. Kumar, R. K. Singh, 'Leishmaniasis: current status of available drugs and new potential drug targets', Asian Pac. J. Trop. Dis. 2012, 5, 485-497.

[20] S. Sundar, J. Chakravarty, 'Leishmaniasis: an update of current pharmacotherapy', Exp. Op. Pharmacother. 2013, $14,53-63$.

[21] S. Burza, R. Mahajan, P. K. Sinha, J. van Griensven, K. Pandey, M. A. Lima, M. G. Sanz, T. Sunyoto, S. Kumar, G. Mitra, 'Visceral leishmaniasis and HIV co-infection in Bihar, India: long-term effectiveness and treatment outcomes with liposomal amphotericin B (AmBisome)', PLoS $\mathrm{Ne}$ glected Trop. Dis. 2014, 8, e3053.

[22] V. V. Andrade Neto, E. F. Cunha Junior, V. d. S. Faioes, T. P. Martins, R. L. Silva, L. L. Leon, E. C. T. Santos, 'Leishmaniasis treatment: update of possibilities for drug repurposing', Front. Biosci. 2018. 23, 967-996.

[23] A. Ponte-Sucre, F. Gamarro, J.-C. Dujardin, M. P. Barrett, R. López-Vélez, R. García-Hernández, A. W. Pountain, R. Mwenechanya, B. Papadopoulou, 'Drug resistance and treatment failure in leishmaniasis: A 21st century challenge', PLoS Neglected Trop. Dis. 2017, 11, e0006052.

[24] A. Cronemberger-Andrade, L. Aragao-Franca, C. F. de Araujo, V. J. Rocha, M. da Cruz Borges-Silva, C. P. Figueiras, P. R. Oliveira, L. A. de Freitas, P. S. Veras, L. Pontes de Carvalho, 'Extracellular vesicles from Leishmania-infected macrophages confer an anti-infection cytokine-production profile to naive macrophages', PLoS Neglected Trop. Dis. 2014, 8, e3161.

[25] V. Stone, H. Johnston, R. P. Schins, 'Development of in vitro systems for nanotoxicology: methodological considerations', Crit. Rev. Toxicol. 2009, 39, 613-626.

[26] V. V. G. de Oliveira, M. A. A. de Souza, R. R. M. Cavalcanti, M. V. de Oliveira Cardoso, A. C. L. Leite, V. A. da Silva Junior, R. C. B. Q. de Figueiredo, 'Study of in vitro biological activity of thiazoles on Leishmania (Leishmania) infantum', J. Glob. Antimicrob. Res. 2020, 22, 414-421.

[27] I. S. Chauhan, G. S. Rao, J. Shankar, L. K. S. Chauhan, G. J. Kapadia, N. Singh, 'Chemoprevention of Leishmaniasis: Invitro antiparasitic activity of dibenzalacetone, a synthetic curcumin analog leads to apoptotic cell death in Leishmania donovani', Parasitol. Int. 2018, 67, 627-636.

[28] P. Chaubey, B. Mishra, S. L. Mudavath, R. R. Patel, S. Chaurasia, S. Sundar, V. Suvarna, M. Monteiro, 'Mannoseconjugated curcumin-chitosan nanoparticles: Efficacy and toxicity assessments against Leishmania donovani', Int. J. Biol. Macromol. 2018, 111, 109-120.

[29] S. Asthana, A. K. Jaiswal, P. K. Gupta, V. K. Pawar, A. Dube, M. K. Chasia, 'Immunoadjuvant chemotherapy of visceral leishmaniasis in hamsters using amphotericin B-encapsulated nanoemulsion template-based chitosan nanocapsules', Antimicrob. Agents Chemother. 2013, 57, 1714-1722.

[30] R. Salah-Tazdaït, D. Tazdaït, Z. Harrat, N. Eddaikra, F. Moulti-Mati, N. Abdi, N. Mameri, 'Antileishmanial activity of low molecular weight chitin prepared from shrimp shell waste', in: Multidisciplinary Approaches for Studying and Combating Microbial Pathogens, by A. Mendes-Vilas (Ed), BrownWalker Press, Boca Raton, USA, 2015, 39-43.

[31] M. H. M. Hoseini, M. Moradi, M. H. Alimohammadian, V. K. Shahgoli, H. Darabi, A. Rostami, 'Immunotherapeutic effects of chitin in comparison with chitosan against 
Leishmania major infection', Parasitol. Int. 2016, 65, 99104.

[32] A. Riezk, K. Van Bocxlaer, V. Yardley, S. Murdan, S. L. Croft, 'Activity of Amphotericin B-Loaded Chitosan Nanoparticles against Experimental Cutaneous Leishmaniasis', Molecules 2020, 25, 4002.

[33] R. El Hajj, Efficacité d'un analog d'Imiqualines, I'EAPB0503: Un nouveau traitement prometteur contre la Leishmaniose Cutanée, in Thèse de doctorat en Biologie Santé, cadre de Sciences Chimiques et Biologiques pour la Santé (Montpellier; Ecole Doctorale), en partenariat avec Institut des Biomolécules Max Mousseron (Montpellier), 2018.

[34] C. S. F. Marques, N. S. Barreto, S. S. C. d. Oliveira, A. L. S. Santos, M. H. Branquinha, D. P. d. Sousa, M. Castro, L. N. Andrade, M. M. Pereira, C. F. d. Silva, M. V. Chaud, S. Jain, A. T. Fricks, E. B. Souto, P. Severino, ' $\beta$-Cyclodextrin/ Isopentyl Caffeate Inclusion Complex: Synthesis, Characterization and Antileishmanial Activity', Molecules 2020, 25, 4181.

[35] S. S. C. Oliveira, C. S. F. Marques, D. P. de Sousa, L. N. Andrade, A. T. Fricks, S. Jain, M. H. Branquinha, E. B. Souto, A. L. S. Santos, P. Severino, 'Analysis of the mechanisms of action of isopentenyl caffeate against Leishmania', Biochimie 2021, 189, 158-167.

[36] J. Brindha, M. M. Balamurali, K. Chanda, 'An Overview on the Therapeutics of Neglected Infectious Diseases-Leishmaniasis and Chagas Diseases', Front. Chem. 2021, 9.

[37] C. S. Freitas, D. P. Lage, J. A. Oliveira-da-Silva, R. R. Costa, D. V. C. Mendonça, V. T. Martins, T. A. R. Reis, L. M. R. Antinarelli, A. S. Machado, G. S. V. Tavares, F. F. Ramos, R. C. F. Brito, F. Ludolf, M. A. Chávez-Fumagalli, B. M. Roatt, G. S. Ramos, J. Munkert, F. M. Ottoni, P. R. V. Campana, M. C. Duarte, D. U. Gonçalves, E. S. Coimbra, F. C. Braga, R. M. Pádua, E. A. F. Coelho, 'In vitro and in vivo antileishmanial activity of $\beta$-acetyl-digitoxin, a cardenolide of Digitalis lanata potentially useful to treat visceral leishmaniasis', Parasite (Paris, France) 2021, 28, 38.

[38] W. Huang, N. Percie du Sert, J. Vollert, A. S. C. Rice, 'General Principles of Preclinical Study Design', Hand. Exp. Pharmacol. 2020, 257, 55-69.

[39] J. A. Cavagnaro, 'Preclinical safety evaluation of biotechnology-derived pharmaceuticals', Nat. Rev. Drug Discovery 2002, 1, 469-475.

[40] P. Bilbao-Ramos, D. R. Serrano, H. K. Ruiz Saldaña, J. J. Torrado, F. Bolás-Fernández, M. A. Dea-Ayuela, 'Evaluating the potential of ursolic acid as bioproduct for cutaneous and visceral leishmaniasis', Molecules 2020, 25, 1394.

[41] N. R. F. do Nascimento, F. L. N. de Aguiar, C. F. Santos, A. M. L. Costa, D. de Jesus Hardoim, K. da Silva Calabrese, F. Almeida-Souza, E. H. S. de Sousa, L. G. de França Lopes, M. J. Teixeira, 'In vitro and in vivo leishmanicidal activity of a ruthenium nitrosyl complex against Leishmania (Viannia) braziliensis', Acta Trop. 2019, 192, 61-65.

[42] K. Horiuchi, S. Shiota, T. Hatano, T. Yoshida, T. Kuroda, T. Tsuchiya, 'Antimicrobial activity of oleanolic acid from Salvia officinalis and related compounds on vancomycinresistant enterococci (VRE)', Biol. Pharm. Bull. 2007, 30, $1147-1149$.

[43] T. G. Soyer, D. V. Mendonça, G. S. Tavares, D. P. Lage, D. S. Dias, P. A. Ribeiro, L. Perin, F. Ludolf, V. T. Coelho, A. C. Ferreira, 'Evaluation of the in vitro and in vivo antileishma- nial activity of a chloroquinolin derivative against Leishmania species capable of causing tegumentary and visceral leishmaniasis', Exp. Parasitol. 2019, 199, 30-37.

[44] T. Marcusso Orsini, N. Y. Kawakami, C. Panis, A. P. Fortes dos Santos Thomazelli, F. Tomiotto-Pellissier, A. H. D. Cataneo, D. Kian, L. Megumi Yamauchi, F. S. Gouveia Júnior, L. G. de França Lopes, 'Antileishmanial activity and inducible nitric oxide synthase activation by RuNO complex', Med. Inflamm. 2016, 2016. Article ID 2631625.

[45] L. Staurengo-Ferrari, S. S. Mizokami, J. J. Silva, F. O. da Silva, E. H. Sousa, L. G. da França, M. L. Matuoka, S. R. Georgetti, M. M. Baracat, R. Casagrande, 'The ruthenium NO donor, $[\mathrm{Ru}$ (bpy) 2 (NO) SO3](PF6), inhibits inflammatory pain: involvement of TRPV1 and cGMP/PKG/ATP-sensitive potassium channel signaling pathway', Pharmacol. Biochem. Behav. 2013, 105, 157-165.

[46] M. W. S. Campelo, R. B. Oriá, L. G. de França Lopes, G. A. de Castro Brito, A. A. dos Santos, R. C. de Vasconcelos, F. O. N. da Silva, B. N. Nobrega, M. T. Bento-Silva, P. R. L. de Vasconcelos, 'Preconditioning with a novel metallopharmaceutical NO donor in anesthetized rats subjected to brain ischemia/reperfusion', Neurochem. Res. 2012, 37, 749-758.

[47] E. H. Silva Sousa, L. A. Ridnour, F. n. S. Gouveia Jr, C. D. Silva da Silva, D. A. Wink, L. G. de França Lopes, P. J. Sadler, 'Thiol-activated HNO release from a ruthenium antiangiogenesis complex and HIF-1 $\alpha$ inhibition for cancer therapy', ACS Chem. Biol. 2016, 11, 2057-2065.

[48] J. J. N. Silva, P. M. M. Guedes, A. Zottis, T. L. Balliano, F. O. Nascimento Silva, L. G. França Lopes, J. Ellena, G. Oliva, A. D. Andricopulo, D.W. Franco, 'Novel ruthenium complexes as potential drugs for Chagas's disease: enzyme inhibition and in vitro/in vivo trypanocidal activity', Br. J. Pharmacol. 2010, 160, 260-269.

[49] A. P. M. Santana, B. M. Tavares, L. T. Lucetti, F. S. Gouveia Jr, R. A. Ribeiro, P. M. Soares, E. H. Sousa, L. G. Lopes, J.-V. R. Medeiros, M. H. Souza, 'The nitric oxide donor cis-[Ru (bpy) 2 (SO3) NO](PF6) increases gastric mucosa protection in mice-Involvement of the soluble guanylate cyclase/KATP pathway', Nitric Oxide 2015, 45, 35-42.

[50] J. C. M. Pereira, V. Carregaro, D. L. Costa, J. S. da Silva, F. Q. Cunha, D. W. Franco, 'Antileishmanial activity of ruthenium (II) tetraammine nitrosyl complexes', Eur. J. Med. Chem. 2010, 45, 4180-4187.

[51] K. A. da Franca Rodrigues, D. K. F. Silva, V. de Lima Serafim, P. N. Andrade, A. F. Alves, W. L. Tafuri, T. M. Batista, V. M. Mangueira, M. V. Sobral, R. O. de Moura, 'SB-83, a 2-Aminothiophene derivative orally bioavailable candidate for the leishmaniasis treatment', Biomed. Pharmacother. 2018, 108, $1670-1678$.

[52] A. E.-G. E. Amr, M. H. Sherif, M. G. Assy, M. A. Al-Omar, I. Ragab, 'Antiarrhythmic, serotonin antagonist and antianxiety activities of novel substituted thiophene derivatives synthesized from 2-amino-4, 5, 6, 7-tetrahydro-N-phenylbenzo [b] thiophene-3-carboxamide', Eur. J. Med. Chem. 2010, 45, 5935-5942.

[53] E. Aguilera, C. Perdomo, A. Espindola, I. Corvo, P. FaralTello, C. Robello, E. Serna, F. Benítez, R. Riveros, S. Torres, 'A Nature-Inspired Design Yields a New Class of Steroids Against Trypanosomatids', Molecules 2019, 24, 3800. 
[54] M. Van den Kerkhof, D. Mabille, E. Chatelain, C. Mowbray, S. Braillard, S. Hendrickx, L. Maes, G. Caljon, 'In vitro and in vivo pharmacodynamics of three novel antileishmanial lead series', Int. J. Parasitol. 2018, 8, 81-86.

[55] K. Van Bocxlaer, D. Caridha, C. Black, B. Vesely, S. Leed, R. J. Sciotti, G.-J. Wijnant, V. Yardley, S. Braillard, C. E. Mowbray, 'Novel benzoxaborole, nitroimidazole and aminopyrazoles with activity against experimental cutaneous leishmaniasis', Int. J. Parasitol. 2019, 11, 129-138.

[56] S. Wyllie, M. Thomas, S. Patterson, S. Crouch, M. De Rycker, R. Lowe, S. Gresham, M. D. Urbaniak, T. D. Otto, L. Stojanovski, 'Cyclin-dependent kinase 12 is a drug target for visceral leishmaniasis', Nature 2018, 560, 192-197.

[57] A. Efstathiou, D. Smirlis, 'Leishmania Protein Kinases: Important Regulators of the Parasite Life Cycle and Molecular Targets for Treating Leishmaniasis', Microorganisms 2021, 9, 691.

[58] S. Wyllie, S. Brand, M. Thomas, M. De Rycker, C.-W. Chung, I. Pena, R. P. Bingham, J. A. Bueren-Calabuig, J. Cantizani, D. Cebrian, 'Preclinical candidate for the treatment of visceral leishmaniasis that acts through proteasome inhibition', Proc. Nat. Acad. Sci. 2019, 116, 9318-9323.

[59] A. M. Thompson, A. Blaser, B. D. Palmer, R. F. Anderson, S. S. Shinde, D. Launay, E. Chatelain, L. Maes, S. G. Franzblau, B. Wan, '6-Nitro-2, 3-dihydroimidazo [2, 1-b][1, 3] thiazoles: Facile synthesis and comparative appraisal against tuberculosis and neglected tropical diseases', Bioorg. Med. Chem. Lett. 2017, 27, 2583-2589.

[60] W. G. Lima, M. C. Ramos-Alves, A. C. Soares, 'Dos distúrbios psiquiátricos à antibioticoterapia: reposicionamento da clorpromazina como agente antibacteriano', Rev. Colomb. Cienc. Quim.-Farm. 2019, 48, 5-28.

[61] J. Fantini, C. Di Scala, H. Chahinian, N. Yahi, 'Structural and molecular modelling studies reveal a new mechanism of action of chloroquine and hydroxychloroquine against SARS-CoV-2 infection', Int. J. Antimicrob. Agents 2020, 55, 105960.

[62] G. Galindez, J. Matschinske, T.D. Rose, S. Sadegh, M. Salgado-Albarrán, J. Späth, J. Baumbach, J.K. Pauling, 'Lessons from the COVID-19 pandemic for advancing computational drug repurposing strategies', Nature Comp. Sci. 2021, 1, 33-41.

[63] S. G. V. Rosa, W. C. Santos, 'Clinical trials on drug repositioning for COVID-19 treatment', Rev. Panam. Salud Publica 2020, 44, e40.

[64] M. B. Serafin, A. Bottega, V. S. Foletto, T. F. d. Rosa, R. F. Rampelotto, F. A. Carvalho, R. Hörner, 'Synergistic effect of sertraline and disulfiram against multidrug resistant bacteria as a new alternative to drug repositioning', Braz. J. Pharm. Sci. 2020, 56.

[65] J. H. da Silva Rodrigues, N. Miranda, H. Volpato, T. UedaNakamura, C. V. Nakamura, 'The antidepressant clomipramine induces programmed cell death in Leishmania amazonensis through a mitochondrial pathway', Parasitol. Res. 2019, 118, 977-989.

[66] M. El Mansari, P. Blier, 'Mechanisms of action of current and potential pharmacotherapies of obsessive-compulsive disorder', Prog. Neuro-Psychopharmacol. Biol. Psychiatry 2006, 30, 362-373.

[67] T. Benson, J. McKie, J. Garforth, A. Borges, A. Fairlamb, K. Douglas, 'Rationally designed selective inhibitors of trypa- nothione reductase. Phenothiazines and related tricyclics as lead structures', Biochem. J. 1992, 286, 9-11.

[68] E. Bemani, A. Oryan, S. Bahrami, 'Effectiveness of amiodarone in treatment of cutaneous leishmaniasis caused by Leishmania major', Exp. Parasitol. 2019, 205, 107747.

[69] M. Ágoston, F. Örsi, E. Fehér, K. Hagymási, Z. Orosz, A. Blázovics, J. Fehér, A. Vereckei, 'Silymarin and vitamin E reduce amiodarone-induced lysosomal phospholipidosis in rats', Toxicology 2003, 190, $231-241$.

[70] S. Cekic, D. Pavlovic, M. Sarac, B. Kamenov, A. Dimic, V. Pavlovic, 'The effect of vitamin $C$ on amiodarone-induced toxicity in rat thymocytes', Open Med. Chem. J. 2011, 6, $58-63$.

[71] A. Jamshidzadeh, M. Baghban, N. Azarpira, A. M. Bardbori, H. Niknahad, 'Effects of tomato extract on oxidative stress induced toxicity in different organs of rats', Food Chem. Toxicol. 2008, 46, 3612-3615.

[72] D. Punithavathi, N. Venkatesan, M. Babu, 'Protective effects of curcumin against amiodarone-induced pulmonary fibrosis in rats', Br. J. Pharmacol. 2003, 139, 1342-1350.

[73] M. W. Roomi, N. W. Roomi, T. Kalinovsky, M. Rath, A. Niedzwiecki, 'Prevention of amiodarone-induced cardiac toxicity in male BALB/c mice by a nutrient mixture', Exp. Therap. Med. 2014, 7, 987-989.

[74] E. de Morais-Teixeira, A. Rabello, M. M. G. Aguiar, 'In vitro activity and in vivo efficacy of fexinidazole against New World Leishmania species', J. Antimicrob. Chemother. 2019, 74, 2318-2325.

[75] R. J. Soares-Bezerra, L. Leon, M. Genestra, 'Recentes avanços da quimioterapia das leishmanioses: moléculas intracelulares como alvo de fármacos', Rev. Bras. Cienc. Farm. 2004, 40, 139- 149.

[76] J. T. Bush, M. Wasunna, F. Alves, J. Alvar, P. L. Olliaro, M. Otieno, C. H. Sibley, N. S. Wourgaft, P. J. Guerin, 'Systematic review of clinical trials assessing the therapeutic efficacy of visceral leishmaniasis treatments: A first step to assess the feasibility of establishing an individual patient data sharing platform', PLoS Neglected Trop. Dis. 2017, 11, e0005781.

[77] DNDi, https://dndi.org/research-development/portfolio/ fexinidazole-vl, 2016.

[78] S. Patterson, S. Wyllie, L. Stojanovski, M. R. Perry, F. R. Simeons, S. Norval, M. Osuna-Cabello, M. De Rycker, K. D. Read, A. H. Fairlamb, 'The R enantiomer of the antitubercular drug PA-824 as a potential oral treatment for visceral leishmaniasis', Antimicrob. Agents Chemother. 2013, 57, 4699-4706.

[79] A. M. Thompson, P. D. O'Connor, A. J. Marshall, V. Yardley, L. Maes, S. Gupta, D. Launay, S. Braillard, E. Chatelain, B. Wan, 'Heteroaryl ether analogs of an antileishmanial 7substituted 2-nitroimidazooxazine lead afford attenuated hERG risk: In vitro and in vivo appraisal', Eur. J. Med. Chem. 2021, 209, 112914.

[80] G.-J. Wijnant, S. L. Croft, R. de la Flor, M. Alavijeh, V. Yardley, S. Braillard, C. Mowbray, K. Van Bocxlaer, 'Pharmacokinetics and pharmacodynamics of the nitroimidazole DNDI-0690 in mouse models of cutaneous leishmaniasis', Antimicrob. Agents Chemother. 2019, 63.

[81] S. Wyllie, A. J. Roberts, S. Norval, S. Patterson, B. J. Foth, M. Berriman, K. D. Read, A. H. Fairlamb, 'Activation of bicyclic nitro-drugs by a novel nitroreductase (NTR2) in Leishmania', PLoS Pathog. 2016, 12, e1005971. 
[82] F. Alves, G. Bilbe, S. Blesson, V. Goyal, S. Monnerat, C. Mowbray, G. M. Ouattara, B. Pécoul, S. Rijal, J. Rode, 'Recent development of visceral leishmaniasis treatments: successes, pitfalls, and perspectives', Clin. Microbiol. Rev. 2018, 31.

[83] DNDi, https://www.dndi.org/diseases-projects/portfolio/oxaborole-dndi-6148, 2018.

[84] DNDi, https://www.isrctn.com/ISRCTN54981564, 2020.

[85] A. Nagle, A. Biggart, C. Be, H. Srinivas, A. Hein, D. Caridha, R. J. Sciotti, B. Pybus, M. Kreishman-Deitrick, B. Bursulaya, 'Discovery and characterization of clinical candidate LXE408 as a kinetoplastid-selective proteasome inhibitor for the treatment of leishmaniases', J. Med. Chem. 2020, 63, 10773-10781.

[86] NOVARTIS, Novartis and DNDi to collaborate on the development of a new oral drug to treat visceral leishmaniasis. Novartis and Drugs for Neglected Diseases initiative (DNDi). in, https://www.novartis.com/news/media-releases/novartis-and-dndi-collaborate-developmentnew-oral-drug-treat-visceral-leishmaniasis (accessed on: $7^{\text {th }}$ January 2021).
[87] E. A. Winzeler, S. Ottilie, 'The proteasome as a target: How not tidying up can have toxic consequences for parasitic protozoa', Proc. Nat. Acad. Sci. 2019, 116, 10198-10200.

[88] GSK, Safety, Tolerability and Pharmacokinetics (PK) Investigation of GSK3494245 in Healthy Participants. GSK clinical trials, United Kingdom., in, https://ichgcp.net/clinical-trialsregistry/NCT04504435 (accessed on: $7^{\text {th }}$ January 2021).

[89] R. El Hajj, H. Bou Youness, L. Lachaud, P. Bastien, C. Masquefa, P.-A. Bonnet, H. El Hajj, I. Khalifeh, 'EAPB0503: An Imiquimod analog with potent in vitro activity against cutaneous leishmaniasis caused by Leishmania major and Leishmania tropica', PLoS Neglected Trop. Dis. 2018, 12, e0006854.

[90] A. Oryan, S. Bahrami, E. Bemani, 'Efficacy of voriconazole on leishmaniasis by Leishmania major: An in vitro and in vivo study', Asian Pac. J. Trop. Med. 2018, 11, 562.

Received April 27, 2021

Accepted July 13, 2021 